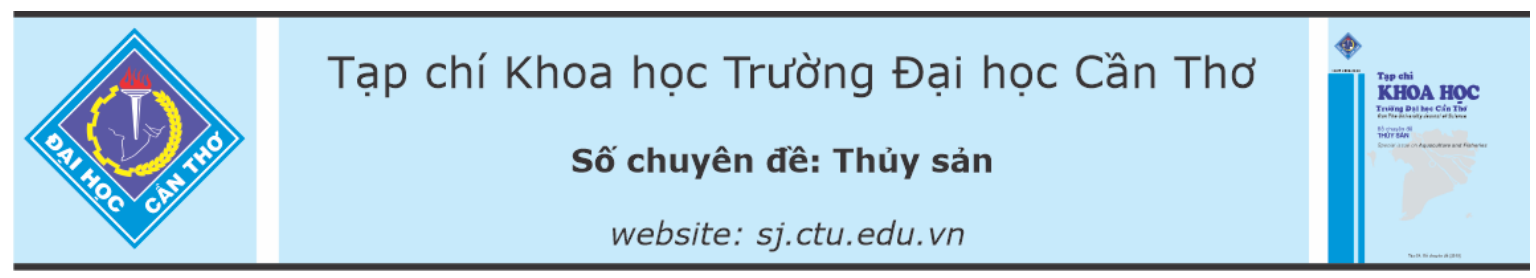

DOI:10.22144/ctu.jvn.2021.062

\title{
MỘT SỐ ĐẶC ĐIỂM SINH HỌC SINH SẢN CỦA CÁ LÀNH CANH (Coilia rebentischii Bleeker, 1858) PHẦ BỐ VÙNG CỬA SÔNG HậU
}

\author{
Võ Thành Toàn ${ }^{1 *}$, Trương Thanh Dinh ${ }^{2}$, Đặng Thụy Mai Thy ${ }^{1}$ và Trần Đắc Định ${ }^{1}$ \\ ${ }^{1}$ Khoa Thủy sản, Truòng Đại học Cần Tho \\ ${ }^{2}$ Hoc viên cao học ngành Nuôi trồng thủy sản khóa 24, Truò̀ng Đại học Cần Tho \\ *Nguò̀i chịu trách nhiệm về bài viết: Võ Thành Toàn (email: vttoan@ctu.edu.vn)
}

\section{Thông tin chung:}

Ngày nhận bài: $22 / 02 / 2021$

Ngày nhận bài sưa: $25 / 04 / 2021$

Ngày duyệt đăng: 01/06/2021

Title:

Study on the reproductive characteristics of Coilia rebentischii Bleeker, 1858 distributed at the estuary of the Hau River

\section{Tù khóa:}

Cá lành canh, đặc điểm sinh sản, sông Hậu

\section{Keywords:}

Coilia rebentischii, Hau river, Reproductive characteristics

\begin{abstract}
This study is aimed to observe the reproductive biology of Coilia rebentischii distributed from downstream of the Hau river (one of the branches of the Mekong River) to the estuary of Dinh An and Tran De, in order to supplement the existing scientific data and to serve as a basis for research on artificial reproduction. The study was conducted from July 2019 to June 2020 by collecting fish samples in three sites from downstream of the Hau River and the estuary of Dinh An and Tran De; the sampling cycle time was once a month by trawl net, bag net and landing net, a number of fish about 40 individuals per month. The results showed that gonadosomatic index (GSI) of Coilia rebentischii ranged from 1.10 to $6.92 \%$ and was more fluctuated than hepatosomatic index (HSI) (from 0.21 to $1.20 \%$ ); conditional factor $(C F)$ of fish was also less fluctuating, in which $C F$ reached the highest value in November. Fecundity of Coilia rebentischii ranged from 218-943 eggs $/ \mathrm{g}$ offemale ( mean $=495 \pm 197 \mathrm{eggs} / \mathrm{g}$ ) with total length was $10.4 \pm 1.8 \mathrm{~cm}$ and total weight was $16.01 \pm 8.05 \mathrm{~g}$. First length mature offemale was $11.05 \mathrm{~cm}$ and male was $13.69 \mathrm{~cm}$. The results also show that the breeding season of Coilia rebentischii begin from June to November and is most concentrated from June to July of the year. This shows that healthy fish is a species that has the potential to develop as a target for breeding because their breeding season is quite long and the reproductive power was also relatively high.
\end{abstract}

\section{TÓM TẮT}

Nghiên cứu một số đặc điểm sinh học sinh sản của cá lành canh (Coilia rebentischii) được thực hiện ở khu vực cuối nguồn sông Hậu tại ba vị trí thuộc cửa sông Trần Đề và Định An tù̀ tháng 7 năm 2019 đến tháng 6 năm 2020. Các mẫu cá lành canh đã được thu trong 12 tháng và thu liên tục 1 tháng/lần bằng luoói kéo, luoói đáy và vơt luới với cõ mẫu it nhất 40 cá thể/tháng. Kết quả cho thấy hệ số thành thục (gonadosomatic index-GSI) của cá lành canh dao động tù 1,10-6,92\% và biến động nhiều hơn so với hệ số tích luỹ năng luợng (hepatosomatic index-HSI) (tù 0,211,20\%); nhân tố điều kiện (conditional factor-CF) của cá lành canh it biến động và giá trị CF đạt cao nhất ở tháng 11. Sức sinh sản của cá lành canh khá cao $(495 \pm 197$ trúng/g cá cái) và có sụ biến động lớn (218-943 trứng/g cá cái) ở kích cỡ trung bình

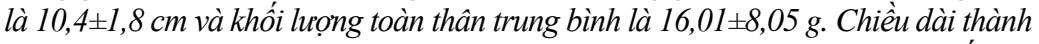
thuc $\left(L_{m}\right)$ của cá lành canh đực là $11,05 \mathrm{~cm}$ và cá lành canh cái là $13,69 \mathrm{~cm}$. Kết quả cũng cho thấy mùa vu sinh sản của cá lành canh khá dài kéo dài tù tháng 6 đến tháng 11 và tập trung nhiều nhất tì̀ tháng 6-7 trong năm. Qua đó cho thấy cá lành canh là loài có tiềm năng phát triển thành đối tượng nuôi vì mùa vu sinh sản của chúng khá dài và súc sinh sản cũng tương đối cao. 


\section{GIỚI THIỆ}

Cá lành canh (Coilia rebentischii Bleeker, 1858) là loài cá quen thuộc với người dân Tây Nam Bộ. Cá lành canh thuộc họ Cyprinidea, bộ Cypriniformes (cá chép) là loài cá sống ở vùng cửa sông, sinh sống tự nhiên được cả nước ngọt, lợ và mặn (Trương Thủ Khoa \& Trần Thị Thu Hương, 1993). Ở Việt Nam, nhóm cá lành canh có nhiều tên như: cá lành canh, cá lành canh xiêm, cá lành canh chóp vàng,... chúng được khai thác chủ yếu bằng lưới kéo. Trong đó, cá lành canh vàng (Coilia rebentischii Bleeker, 1858) là một trong những loài đã được ghi nhận thuộc giống Coilia của bộ cá trích Clupeiformes (Froese \& Pauly, 2020) và phân bố chủ yếu ở vùng cửa sông ven biển của Đồng bằng sông Cửu Long (ĐBSCL) (Trần Đắc Định \& Hồng Thị Hải Yến, 2019), không chỉ phong phú về sản lượng và thành phần loài mà còn có giá trị dinh dưỡng cao và là nhóm cá có giá trị kinh tế ở vùng ĐBSCL. Loài cá này cũng được ghi nhận xuất hiện chủ yếu ở vùng cửa sông ven biển, một số được tìm thấy ở vùng nước ngọt (Cao Hoài Đức và ctv., 2014; Thái Ngọc Trí, 2015). Các loài cá này khá phong phú về sản lượng và thành phần loài, trong đó loài Coilia rebentischii có giá trị dinh dưỡng khá cao. Tuy nhiên, thông tin về loài cá này ở ĐBSCL còn hạn chế. Vì vậy, việc nghiên cứu một số đặc điểm sinh sản của loài Coilia rebentischii là rất cần thiết, qua đó góp phần bổ sung các thông tin khoa học và làm cơ sở cho việc khai thác, quản lý và sử dụng hợp lý nguồn lợi nhóm cá này ở khu vực ĐBSCL.

\section{PHƯƠNG PHÁP NGHIÊN CÚU}

\subsection{Thời gian và địa điểm nghiên cứu}

Mẫu cá lành canh (Coilia rebentischii) được thu trong 12 tháng và thu liên tục 1 tháng/lần từ tháng 7 năm 2019 đến tháng 6 năm 2020 (Hình 1). Cá lành canh được thu tại 3 vị trí ở khu vực cuối nguồn sông Hậu từ Đại Ngãi đến cửa sông Trần Đề, tỉnh Sóc Trăng (Hình 2).

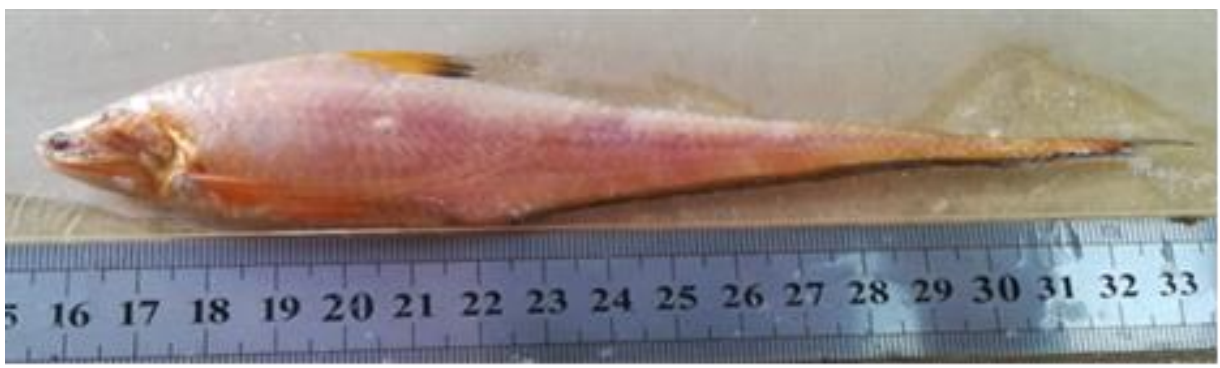

Hình 1. Cá lành canh (Coilia rebentischii)

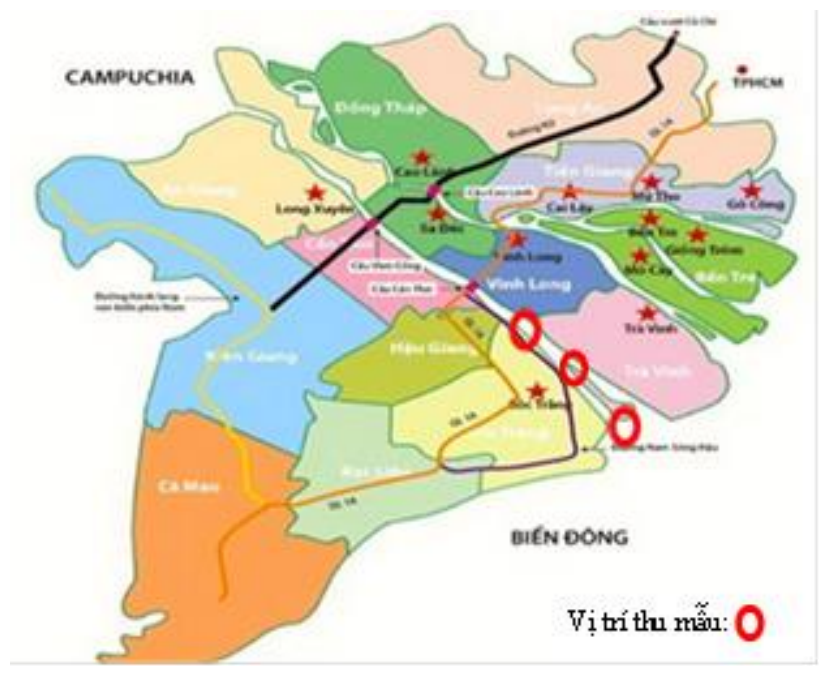

Hình 2. Địa điểm thu mẫu vùng hạ lưu sông Hậu 


\subsection{Phương pháp thu và phân tích số liệu}

Các chỉ tiêu sinh thái như nhiệt độ, pH, độ mặn có liên quan trực tiếp đến sự phân bố và hoạt động sinh sản của cá lành canh được thu thập tại hiện trường bằng các dụng cụ chuyên dụng như: nhiệt kế, pH kế và khúc xạ kế.

Các mẫu cá lành canh được thu ngẫu nhiên ít nhất là 40 cá thể/tháng từ mẫu thu được bằng lưới kéo, lưới đáy và vợt lưới để xác định chiều dài tổng $(\mathrm{TL}, \mathrm{cm})$, chiều dài chuẩn $(\mathrm{SL}, \mathrm{cm})$, khối lượng toàn thân (TW, g), khối lượng tuyến sinh dục $\left(\mathrm{W}_{\mathrm{tsd}}, \mathrm{g}\right)$, khối lượng gan $\left(\mathrm{W}_{\mathrm{g}}, \mathrm{g}\right)$, khối lượng không nội quan $\left(\mathrm{W}_{\mathrm{o}}, \mathrm{g}\right)$ và các giai đoạn phát triển của tuyến sinh dục cá. Các chỉ tiêu về chiều dài được xác định bằng thước kẹp cơ $(\mathrm{cm})$ và các chỉ tiêu về khối lượng được phân tích bằng cân điện tử $(0,01 \mathrm{~g})$.

(i) Hệ số thành thục sinh dục (gonadosomatic index - GSI) là một hệ số để dự đoán mùa vụ sinh sản của cá, sự thay đổi theo mùa của khối lượng tuyến sinh dục cá có thể thấy rõ ràng ở trên cá thể cái do sự gia tăng nhanh về khối lượng của sản phẩm sinh dục cá. GSI của cá lành canh được xác định cho từng tháng và dựa theo công thức $\mathrm{GSI}=(\mathrm{GW} / \mathrm{BW}) * 100$ (Biswas, 1993), trong đó: $\mathrm{GW}$ là khối lượng tuyến sinh dục cá $(\mathrm{g}) ; \mathrm{BW}$ là là khối lượng toàn thân cá $(\mathrm{g})$.

(ii) Hệ số tích luỹ năng lượng (HSI) của cá lành canh cũng được xác định cho từng tháng và dựa theo công thức $\mathrm{HSI}=(\mathrm{LW} /(\mathrm{BW}) * 100$ (Miller, 1984), trong đó: $\mathrm{LW}$ là khối lượng gan cá $(\mathrm{g}) ; \mathrm{BW}$ là khối lượng thân cá $(\mathrm{g})$.

(iii) Hệ số điều kiện $(\mathrm{CF})$ để phát hiện sự thay đổi về mùa vụ xuất hiện của cá và sự thay đổi này do sự phong phú về thức ăn và mùa vụ sinh sản của đàn cá. $\mathrm{CF}$ được xác định theo công thức $\mathrm{CF}=\mathrm{W} / \mathrm{L}^{\mathrm{b}}$ (King, 1995), với W: là khối lượng thân cá $(\mathrm{g}) ; \mathrm{L}$ : là chiều dài chuẩn $(\mathrm{cm})$; b: là hệ số tăng trưởng (được tính dựa vào mối tương quan giữa chiều dài và khối lượng thân cá).

(iv) Sức sinh sản được xác định dựa vào khối lượng buồng trứng và số lượng trứng trong một mẫu trứng đại diện, trong đó mẫu trứng (từ giai đoạn III đến giai đoạn IV) được lấy tại 3 vị trí là phần đầu, phần giữa và phần cuối của buồng trứng và được tính theo công thức của Banegal (1967): $\mathrm{PF}=\left(\mathrm{n}^{*} \mathrm{G}\right) / \mathrm{g}$, trong đó: $\mathrm{G}$ là khối lượng buồng trứng (g); $\mathrm{g}$ là khối lượng mẫu cá được lấy đại diện $(\mathrm{g}) ; \mathrm{n}$ là số lượng trứng có trong mẫu đại diện (trứng).

(v) Các giai đoạn thành thục sinh dục được sử dụng để xác định mức độ thành thục sinh dục của cá, dựa theo mô tả bậc thang thành thục sinh dục của Vesey \& Langford (1985) với 6 giai đoạn phát triển. Bậc thang thành thục này cho phép đánh giá nhanh mức độ thành thục và khả năng sinh sản của cá lành canh. Ngoài ra, để quan sát đặc điểm của các giai đoạn phát triển tuyến sinh dục của cá (noãn sào và tinh sào) trong nghiên cứu này cũng có sử dụng phương pháp mô học theo mô tả của Drury \& Wallington (1980).

(vi) Kích cỡ thành thục sinh dục của cá lành canh được xác định dựa trên cơ sở đo chiều dài chuẩn của cá và được xác định theo công thức tính của King (1995): $\mathrm{P}=1 /\left\{1+\mathrm{e}^{-\mathrm{r}\left(\mathrm{L}-\mathrm{Lm}_{50}\right.}\right\}$, trong đó, $\mathrm{P}$ : là tỉ lệ cá thành thục $(\%)$, L: là chiều dài trung bình của cá (cm), $\mathrm{L}_{\mathrm{m} 50}$ : là chiều dài thành thục ở $50 \%$ quần đàn cá $(\mathrm{cm})$ và kết hợp với phần mềm Statistica $(8.0)$ để xác định $\mathrm{L}_{\mathrm{m}}$ thông qua mô hình toán học.

\section{KẾT QUẢ VÀ THẢO LUẬN}

\subsection{Một số yếu tố sinh thái có liên quan đến phân bố của cá lành canh}

Kết quả nghiên cứu cho thấy giá trị pH tại ba vị trí khảo sát ở khu vực cửa sông Hậu ít biến động qua các đợt khảo sát (từ $7,1-7,7)$ và $\mathrm{pH}$ trong mùa khô cao hơn mùa mưa, kết quả này phù hợp với nhận định của Trương Quốc Phú (2006), pH thích hợp cho các loài cá phát triển trong thủy vực dao động từ 7,5-8,5. Nhiệt độ nước cũng ít biến động ở ba vị trí (mùa mưa: $29,3-29,9^{\circ} \mathrm{C}$; mùa khô: $29,0-29,7^{\circ} \mathrm{C}$ ). Độ mặn ở tầng mặt chỉ ghi nhận được ở Trần Đề cao hơn so với ở Định An (dao động từ 1,6-5,9\%), trong khi đó độ mặn tầng đáy cao hơn so với tầng mặt và thấp nhất là ở Đại Ngãi (mùa mưa: $0,6 \%$, mùa khô: $1,3 \%$ ), cao nhất ở Định An (mùa mưa: $10,9 \%$, mùa khô: $10,6 \%$ ). Nhìn chung, các yếu tố sinh thái đều nằm trong khoảng thích hợp cho tất cả các loài cá, do đây là thủy vực nước chảy nên thường có sự xáo trộn của khối nước bên trong và sự tác động của chế độ nước vùng cửa sông, tuy có biến động, nhưng vẫn nằm trong khoảng thích hợp cho những loài cá, đặc biệt là thích hợp cho sự phân bố, sinh trưởng và phát triển của cá lành canh.

\subsection{Hệ số thành thục sinh dục (GSI) và hệ số tích lũy năng lượng (HSI)}

Kết quả nghiên cứu trên tổng số 362 mẫu cá (cá cái: 203 , cá đực: 159 ) cho thấy GSI và HSI của cá lành canh đực và cái có biến động nhiều từ tháng 5 11 (Hình 3 ), trong đó GSI của cá cái đạt cao nhất là $4,36 \pm 1,51 \%$ (tháng 7 ) và ở cá đực là $6,92 \pm 5,08 \%$ (tháng 6). GSI thấp nhất ở cá cái là $1,10 \pm 0,92 \%$ (tháng 10), cá đực: $1,18 \pm 1,00 \%$ (tháng 2), trong khi đó hệ số tích lũy năng lượng (HSI) của cá đực là 
$1,10 \pm 0,60 \%$ (tháng 7) và ở cá cái là $0,30 \pm 0,18 \%$ (tháng 10 ). Kết quả này cũng cho thấy hệ số GSI và HSI cá lành canh đực và cái có biến động nhiều qua các tháng, trong đó GSI của cá đực và cá cái đạt cao nhất vào mùa mưa (tháng 6-7) (Hình 3).

GSI và HSI của cá là những hệ số quan trọng để dự đoán mùa vụ sinh sản của cá (Phạm Thanh Liêm \& Trần Đắc Định, 2004) và việc xác định GSI của cá chủ yếu dựa vào tuyến sinh dục. Khối lượng tuyến sinh dục là chỉ tiêu số lượng để đánh giá tình trạng thành thục của cá và được tính cho từng giới tính riêng biệt. Sự thay đổi theo mùa của khối lượng tuyến sinh dục cá có thể thấy khá rõ ràng ở cá cái do

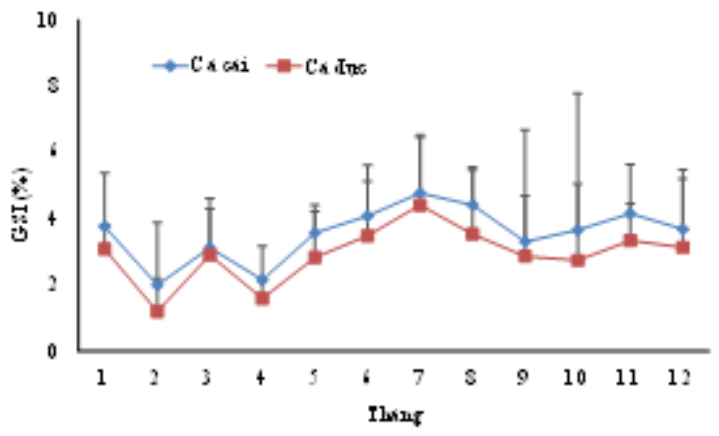

sự gia tăng nhanh về khối lượng của sản phẩm sinh dục của cá. Theo Phạm Minh Thành \& Nguyễn Văn Kiểm (2009), sự lớn lên của tế bào sinh dục cá được quyết định bởi sự chuyển hóa dinh dưỡng nội tại trong cơ thể chúng, đó là sự chuyển hóa các chất từ cơ và gan, khi cá ở giai đoạn có GSI lớn thì HSI thấp và ngược lại. Mặt khác, GSI của cá lành canh đực và cái đều thấp từ tháng $2-4$, sau đó tăng dần từ tháng 6-11 và sự biến động này là do cá lành canh đã tham gia sinh sản trước tháng 1 và tuyến sinh dục của cá chỉ còn lại các tế bào sinh dục ở giai đoạn I và II là chủ yếu.

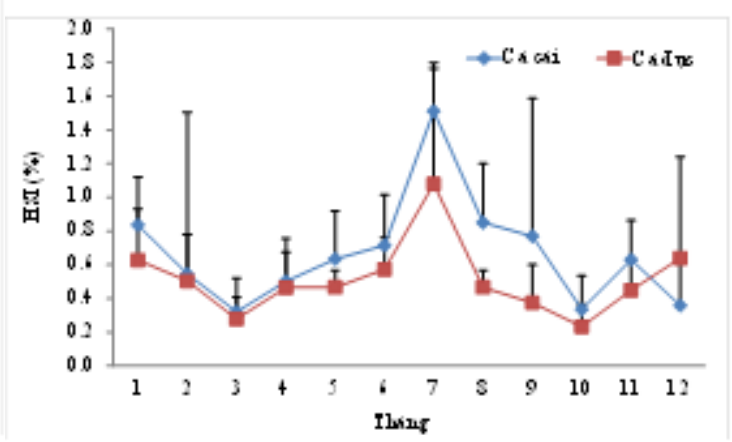

Hình 3. Hệ số thành thục sinh dục (GSI) và hệ số tích luỹ năng lượng (HSI) cá lành canh

\subsection{Hệ số điều kiện $(\mathrm{CF})$}

CF được xác định thông qua hệ số b (hệ số tăng trưởng) từ việc phân tích mối tương quan giữa chiều dài chuẩn và khối lượng thân của cá lành canh và kết quả này được thể hiện qua phương trình hồi qui khi phân tích 157 mẫu cá cái và 198 mẫu cá đực đã thu được trong 12 tháng khảo sát (Hình 4).

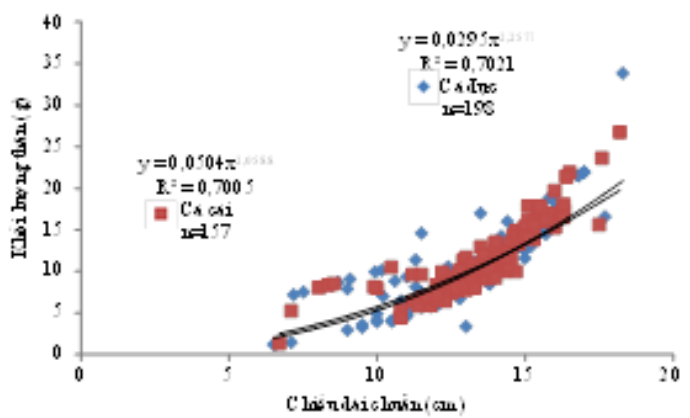

\section{Hình 4. Tương quan giữa chiều dài chuẩn và khối lượng thân của cá lành canh}

Hình 5 cho thấy $C F$ của cá lành canh ít biến động, cao nhất là $0,022 \pm 0,002 \mathrm{~g} / \mathrm{cm}$ (cá cái) và $0,038 \pm 0,003 \mathrm{~g} / \mathrm{cm}$ (cá đực). Theo King (1995), CF được dùng để giá mức độ gia tăng khối lượng của cá so với mức độ gia tăng chiều dài và sự gia tăng nhanh về khối lượng của cá trong một khoảng thời gian nhất định chủ yếu là do sự gia tăng về khối lượng tuyến sinh dục của cá trong giai đoạn thành thục sinh dục của cá, đối với cá cái vào thời điểm có nguồn thức ăn phong phú sẽ sử dụng nhiều thức ăn hơn.

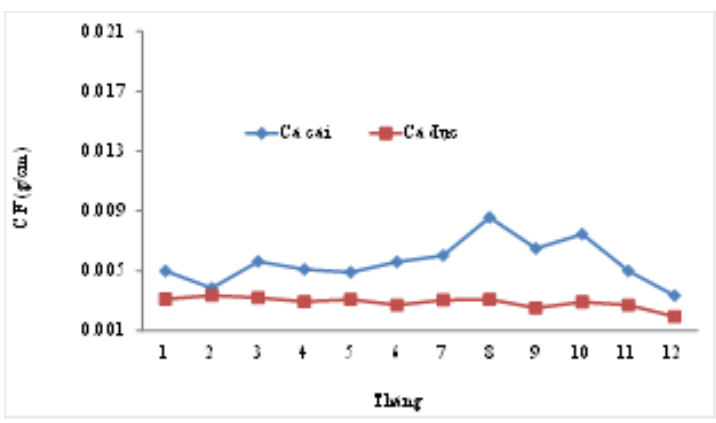

Hình 5. Hệ số điều kiện $(\mathrm{CF})$ cá lành canh

\subsection{Sức sinh sản của cá}

Kết quả nghiên cứu trên 20 mẫu cá lành canh cái đã đạt đển giai đoạn thành thục sinh dục (giai đoạn IV) cho thấy sức sinh sản trung bình của cá lành canh khá cao (495 197 trứng/g cá cái) và có sự biến động nhiều (218-943 trứng/g cá cái) ở kích cỡ trung bình $10,4 \pm 1,8 \mathrm{~cm}$ và khối lượng thân là $16,01 \pm 8,05$ g. Theo Phạm Thanh Liêm \& Trần Đắc Định (2004), 
sức sinh sản của cá thay đổi theo loài và phụ thuộc vào tuổi, kích thước và điều kiện môi trường sống của chúng và những loài cá có tập tính làm tổ đẻ trứng có sức sinh sản thấp (Phạm Minh Thành \& Nguyễn Văn Kiểm, 2009).

\subsection{Các giai đoạn thành thục sinh dục của cá lành canh}

Kết quả cho thấy tỉ lệ các giai đoạn thành thục sinh dục của cá lành canh khác nhau theo giai đoạn phát triển của chúng. Cá chưa thành thục sinh dục (giai đoạn I và II) có sự khác nhau giữa các tháng trong năm và tỉ lệ này cao nhất tập trung vào tháng 7 và tháng 10 (Hình 6), trong khi đó cá đạt đến giai đoạn thành thục (giai đoạn) III được phát hiện quanh năm và thời điểm đạt tỉ lệ cao nhất từ tháng 8 đến tháng 11 với tỉ lệ thành thục cao nhất là $60 \%$. Theo ghi nhận của ngư dân sống dọc theo khu vực cuối nguồn sông Hậu, cá lành canh có trứng xuất hiện nhiều nhất từ tháng $8-9$, trong khi đó tuyến sinh dục của cá cái chỉ phát hiện đến mức độ thành thục sinh dục ở giai đoạn IV và cao nhất là trong tháng 9 và 11 (31-38\%) nhiều hơn so với các tháng còn lại.
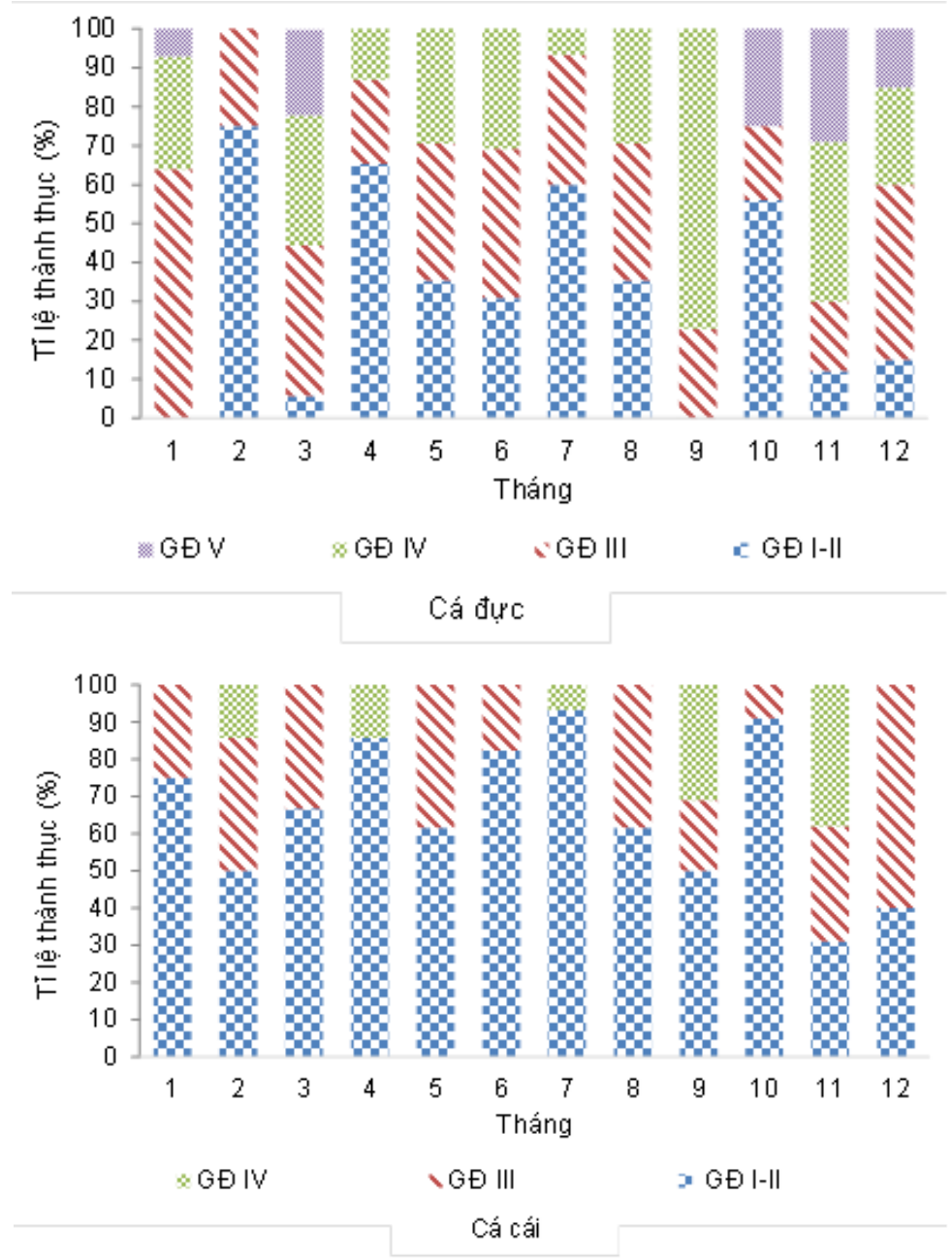

\section{Hình 6. Tỉ lệ (\%) các giai đoạn thành thục sinh dục của cá lành canh đực và cái}

Các giai đoạn thành thục sinh dục của cá lành canh có tỉ lệ khác nhau theo thời gian, ở giai đoạn cá chưa thành thục sinh dục (giai đoạn I và II) có sự khác nhau từ tháng $1-3$ và từ tháng $8-11$ và tî lệ này đạt cao nhất ở tháng $7(90 \%$, Hình 6), trong khi đó chúng đạt giai đoạn thành thục đến giai đoạn IV được phát hiện quanh năm và thời điểm đạt tỉ lệ cao nhất từ tháng 7-11 với tỉ lệ thành thục là $50 \%$, điều này cũng cho thấy mùa vụ sinh sản của cá lành canh là quanh năm và tập trung chủ yếu từ tháng 7 đến tháng 11. Theo 6 giai đoạn thành thục sinh dục được đề nghị bởi Vesey \& Langford (1985), trong nghiên cứu này cá lành canh chỉ phát hiện đến giai đoạn IV, kết quả này cho thấy mùa vụ sinh sản của cá lành 
canh tập trung vào mùa mưa và bắt đầu từ tháng 8 và kết thúc vào tháng 11 (Hình 6) và tập trung nhiều từ tháng 9 đến tháng 11 . Kết quả quan sát mô học cho thấy các giai đoạn phát triển noãn sào của loài Coilia rebentischii được phát hiện chủ yếu từ giai đoạn I đến giai đoạn IV, tuy nhiên trong tiêu bản mô học có phát hiện rải rác một số hạt noãn hoàng đạt đến giai đoạn $\mathrm{V}$ và các hạt noãn hoàng này xuất hiện rất ít (Hình 7). So với kết quả phân tích hình thái của noãn sào cá lành canh thì đa phần các noãn sào đạt đến giai đoạn IV so với 6 giai đoạn đã được mô tả bởi Vesey \& Langford (1985).
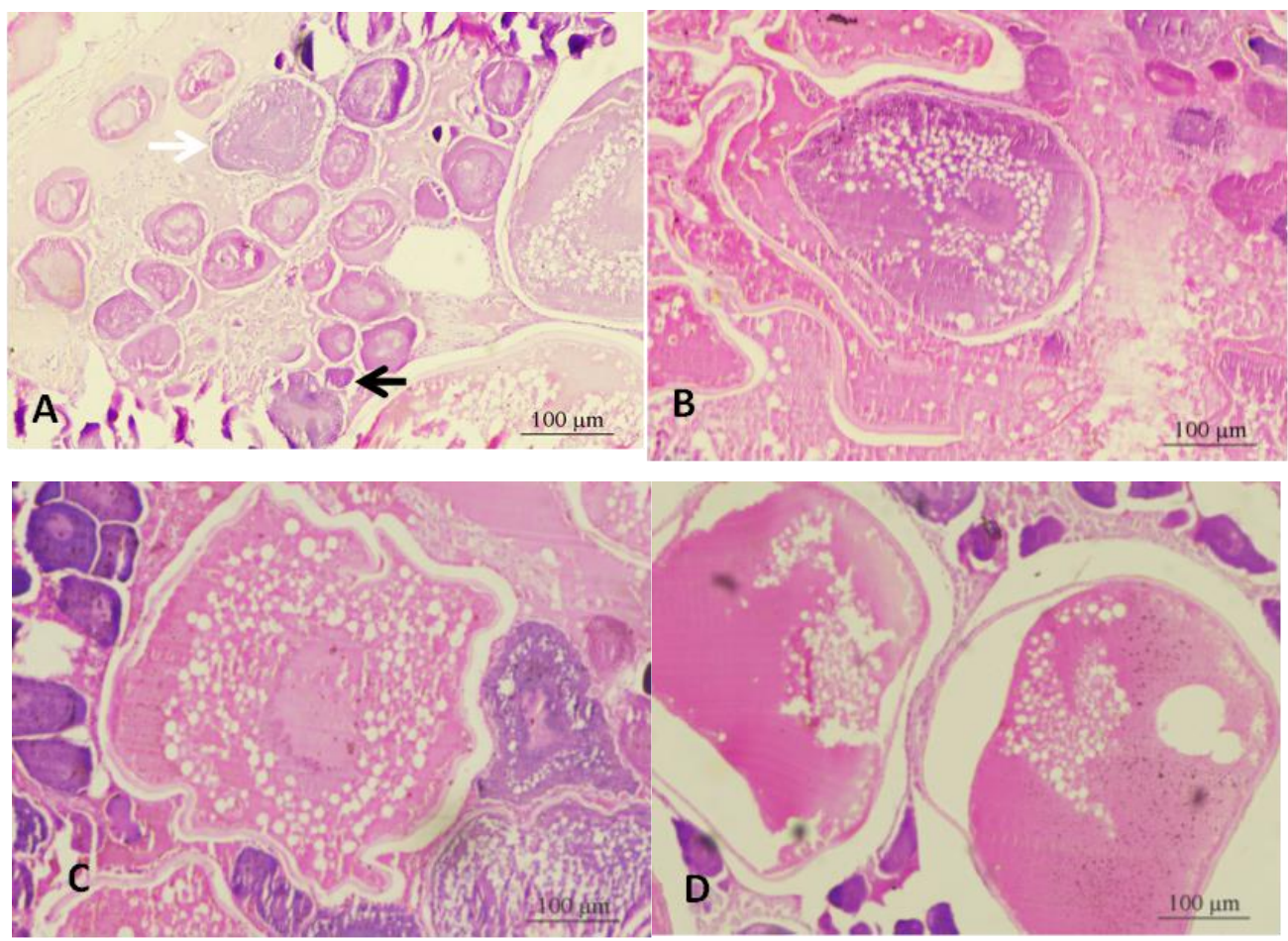

Hình 7. Các giai đoạn phát triển noãn sào của cá lành canh $(\mathrm{H} \& \mathrm{E}, 10 \mathrm{X})$

A: Noãn nguyên bào thời kỳ I (mũi tên đen), Noãn sào thời kỳ II (mũi tên trắng); B: Noãn sào thời kỳ III; C: Noãn sào thờ kỳ IV; D: Noãn sào thòi kỳ V
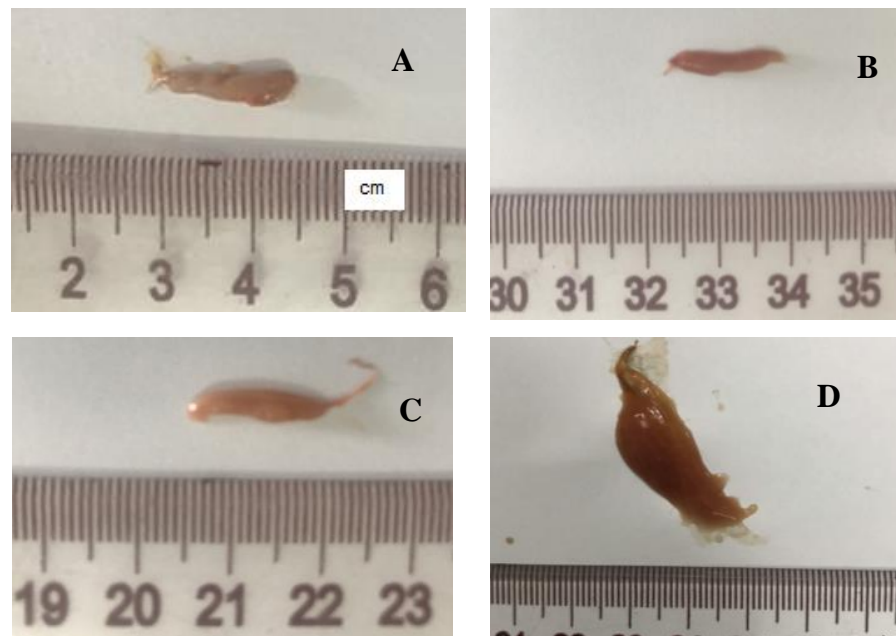

$\begin{array}{lllllll}21 & 22 & 23 & 24 & 25 & 26 & 27\end{array}$

Hình 8. Các giai đoạn phát triển noãn sào của cá lành canh (A: GĐ I, B: GĐ II, C: GĐ III, D: GĐ IV) 
Kết quả quan sát tiêu bản mô học trong nghiên cứu này cho thấy tinh sào của cá lành canh có ít tinh bào sơ cấp và thứ cấp chủ yếu là tinh tử và tinh trùng
(Hình 8), điều này cho thấy đa phần các tinh sào của cá lành canh quan sát được đã đạt đến giai đoạn thành thục sinh dục và cá đang trong thời kỳ tham gia sinh sản.
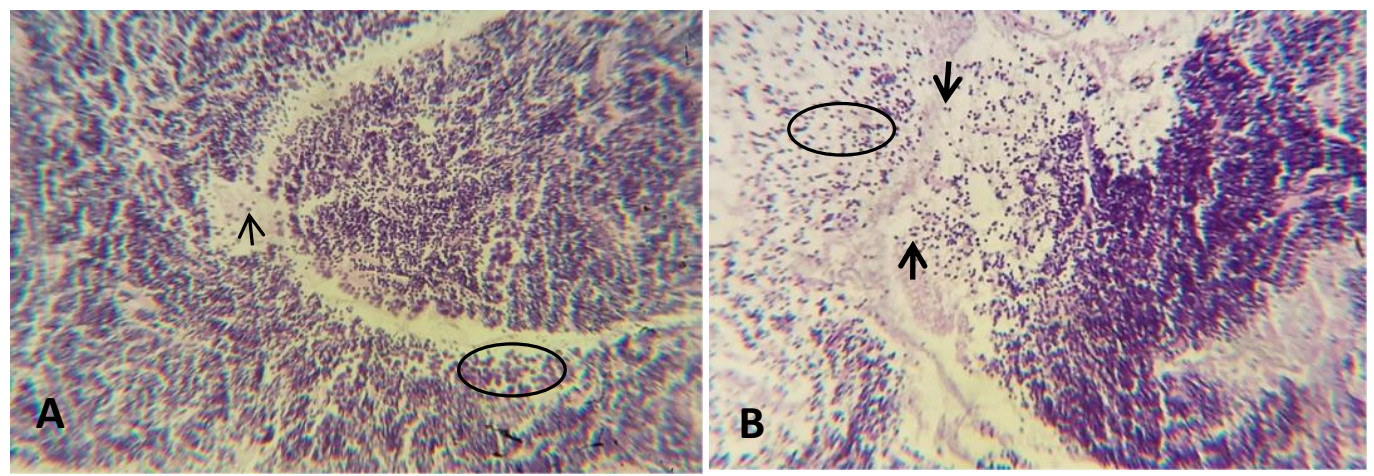

Hình 9. Tinh sào của cá lành canh $(\mathrm{H} \& \mathrm{E})$

A: Tinh bào sơ cấp (vòng tròn), tinh bào thứ cấp (mũi tên); B: Tinh tử (vòng tròn); tinh trùng (mũi tên)

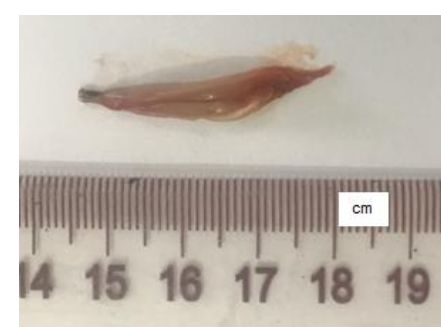

Tinh sào giai đoạn II

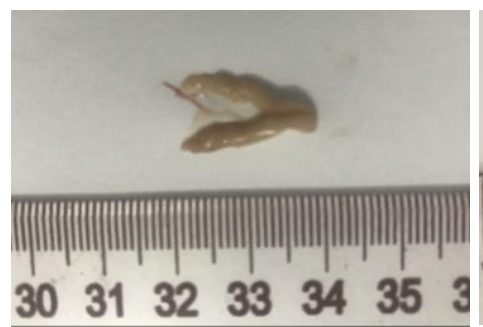

Tinh sào giai đoạn IV

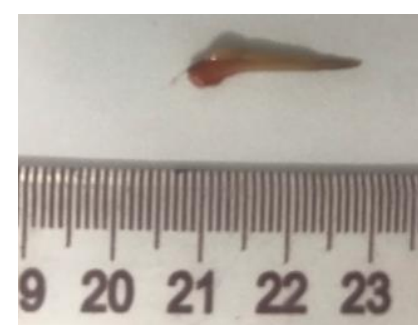

Tinh sào giai đoạn III

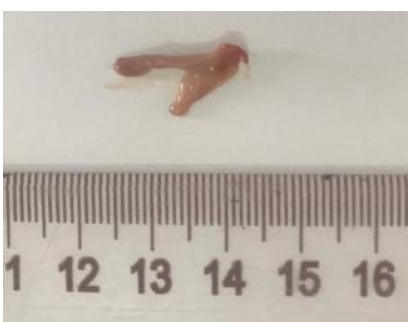

Tinh sào giai đoạn $\mathrm{V}$

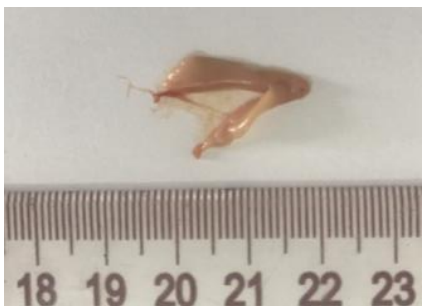

Tinh sào giai đoạn VI

Hình 10. Các giai đoạn phát triển tinh sào của cá lành canh

\subsection{Mùa vụ sinh sản}

Qua kết quả phân tích về sự phát triển của các giai đoạn phát triển tuyến sinh dục, GSI và $\mathrm{HSI}$ ) $\mathrm{CF}$ cho thấy mùa vụ sinh sản của cá lành canh được xác định thông qua các số liệu về khối lượng, tỉ lệ thành thục sinh dục, các hệ số thành thục sinh dục của loài cá này đã đạt đến giai đoạn chín muồi sinh dục (giai 
đoạn IV) và xuất hiện nhiều từ tháng 6 đến tháng 11 , tập trung nhiều nhất từ tháng 6-7 trong năm. Kết quả cho thấy mùa vụ sinh sản của cá lành canh cũng tương tự với các nhóm cá phân bố ở các vùng nước ven bờ và vùng cửa sông (cá lưỡi trâu, cá trích). Theo Phạm Quốc Huy (2011), mùa vụ sinh sản của cá lưỡi trâu chủ yếu tập trung vào các tháng $2-3$ và tháng 7-9, đây là thời gian vào cuối mùa khô và giữa mùa mưa. Theo Minami \& Tanaka (1992), mùa vụ sinh sản của cá được mô tả từ tháng bắt đầu cho đến tháng cá kết thúc chu kỳ sinh sản và thời gian sinh sản của hầu hết các loài cá thường kéo dài trong nhiều tuần đến nhiều tháng do sự khác biệt giữa các cá thể về thời gian cá bắt đầu tham gia sinh sản (Wright \& Trippel, 2009).

\subsection{Kích cỡ thành thục sinh dục của cá lành canh}

Kết quả phân tích 131 mẫu cá lành canh đực và

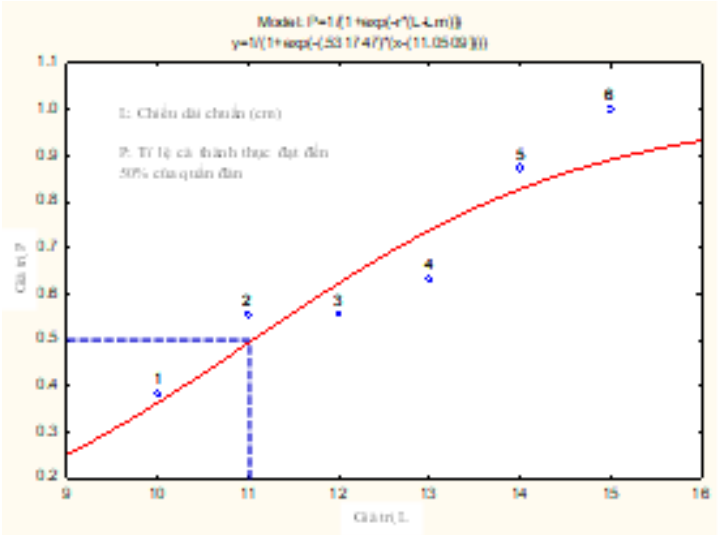

61 mẫu cá cái bằng phần mềm Statistica (8.0) cho thấy chiều dài thành thục $\left(\mathrm{L}_{\mathrm{m}}\right)$ của cá lành canh đực là $11,05 \mathrm{~cm}$ và cá lành canh cái là $13,69 \mathrm{~cm}$ (Hình 11). Theo King (1995), $\mathrm{L}_{\mathrm{m}}$ của cá là chiều dài tại đó quần đàn của cá này có $50 \%$ cá thể trong quần đàn đã phát triển đến giai đoạn thành thục (giai đoạn III). Kết quả $\mathrm{L}_{\mathrm{m}}$ trong nghiên cứu này được dựa theo nguyên lý xác định của King (1995) và đường biểu diễn của chúng có dạng hình chữ $\mathrm{S}$ và một điểm uốn tại đó tỉ lệ cá thành thục đạt $50 \%$ trong quần đàn cá $(\mathrm{P}=0,5)$. Ngoài ra, việc xác định chiều dài thành thục của cá $\left(\mathrm{L}_{\mathrm{m}}\right)$ cũng đã được Udupe (1986) đề cập đến và $\mathrm{L}_{\mathrm{m}}$ là chiều dài của cá khi quần đàn của chúng có ít nhất $50 \%$ số cá thể trong quần đàn đạt đến giai đoạn thành thục sinh dục (từ giai đoạn III). Kết quả nghiên cứu này cho thấy chiều dài thành thục của cá lành canh tương đương so với cá bống tượng (Lawrence et al., 2002).

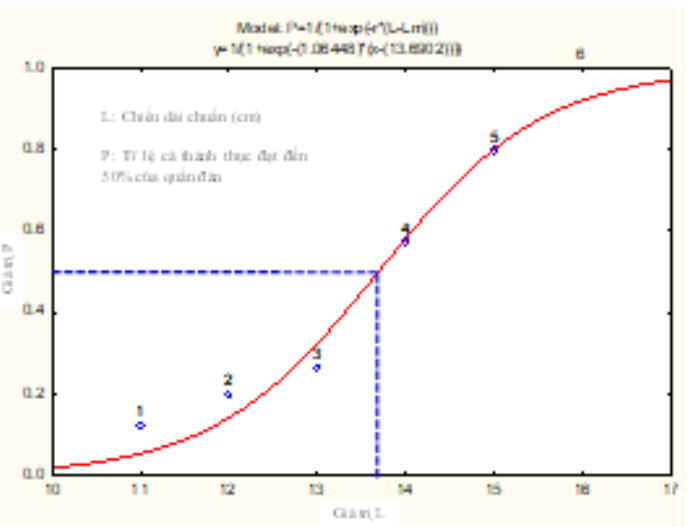

Hình 11. Chiều dài thành thục đầu tiên của cá lành canh

\section{KẾT LUẬN VÀ ĐỀ NGH!}

Cá lành canh có hệ số thành thục sinh dục trung bình cao nhất là tháng 7 , mùa vụ sinh sản của cá lành canh khá dài kéo dài từ tháng 6 đến tháng 11 và tập trung nhiều nhất từ tháng 6-7 trong năm. Sức sinh sản của cá lành canh khá cao $(495 \pm 197$ trứng/g cá cái) và có sự biến động lớn (218-943 trứng/g cá cái) ở kích cỡ trung bình là $10,4 \pm 1,8 \mathrm{~cm}$ và khối lượng toàn thân trung bình là $16,01 \pm 8,05 \mathrm{~g}$. Chiều dài thành thục của cá khá lớn (cá đực: $11,05 \mathrm{~cm}$, cá cái: $13,69 \mathrm{~cm})$.

Cần nghiên cứu về hiện trạng khai thác và khả năng sử dụng nguồn lợi cá lành canh (Coilia rebentischii) để đưa ra những giải pháp khai thác hợp lý, bảo tồn và phục hồi nguồn lợi cá lành canh ở vùng cửa sông ven biển Trần Đề và Định An nói riêng và các vùng cửa sông ở ĐBSCL nói chung.

\section{LỜI CẢM TẠ}

Nghiên cứu này được tài trợ bởi Dự án Nâng cấp Trường Đại học Cần Thơ VN14-P6 bằng nguồn vốn vay ODA từ Chính phủ Nhật Bản.

\section{TÀI LIỆ THAM KHẢO}

Banegal, T. B. (1967). A short review of fish fecundity. In Gerkinh S.D. (Ed.) The Biological Basis of Freshwater Fish Production. Blackwell Scientific, Oxford, p. 98-111.

Biwas, S. P. (1993). Manual of Methods in Fish Biology. South Asian Publishers. Pvt Ltd. New Delhi. 157 pp.

Cao Hoài Đức, Tống Xuân Tám \& Huỳnh Đặng Kim Thủy (2014). Nghiên cứu thành phần loài và đặc điểm phân bố cá ở lưu vực sông Cái Lớn tỉnh Kiên Giang. Tạp chí Khoa học Đại học sư phạm TP. HCM, 61, 132-145. 
Drury, R. A. B. \& Wallington, E. A. (1980). Carleton's histological techniques, 5th Edition. Oxford University Press, London.

Froese, R. \& Pauly, D. (2020). (Eds). Fishbase. Worldwide Web Electronic Publication, Available at www.fishbase.org. Ngày truy cập: 30/6/2020.

King, M. (1995). Fisheries biology, Assessment and management. Fishing News Books, Osney Mead, Oxford OX2 0EL, England. 341 pp.

Lawrence, Richard, E., King, P. \& Udo, M. T. (2002). Breeding, growth, mortality and yield of the mudskipper Periophthalmus ba; KLrbarus (Teleostei: Gobiidae) in the Imo River estuary, Nigeria. Fisheries Research, 56, 227-238.

Miller, P. J. (1984). The Tokology of Gobioid Fish. In Fish Reproduction: Strategies and facties, Edited by G. W. Potts anh R. J. Wootton, p.119153. Academic Press.

Minami, T. \& Tanaka, M. (1992). Life history cycles in flatfish from the northwestern Pacific: with particular reference to their early life histories. Netherlands Journal of Sea Research, 29(1-3), 35-48.

Phạm Minh Thành \& Nguyễn Văn Kiểm. (2009). Cơ sở khoa học và kỹ thuật sản xuất cá giống. Nhà xuất bản nông nghiệp, TP. Hồ Chí Minh.

Phạm Quốc Huy. (2011). Trứng cá-cá con giống cá bơn lưỡi Cynoglossus ở vùng biển ven bờ Đông Tây Nam Bộ. Trong: Nguyễn Quang Hùng (chủ biên). Bản tin Viện nghiên cứu hải sản bộ Nông nghiệp và phát triển nông thôn, 20, 12-16.
Phạm Thanh Liêm \& Trần Đắc Định. (2004). Giáo trình Phương pháp nghiên cứu sinh học cá. Khoa Thủy sản, trường Đại học Cần Thơ. Thành phố Cần Thơ.

Thái Ngọc Trí. (2015). Nghiên cứu đa dạng sinh học khu hệ cá Đồng bằng sông Cửu Long và sự biến đổi của chúng do tác động của biến đổi khí hậu và sự phát triển kinh tế-xã hội. Luận án tiến sĩ sinh học. Học viện khoa học và công nghệ, Viện Hàn lâm Khoa học và công nghệ Việt Nam.

Trần Đắc Định \& Hồng Thị Hải Yến. (2019). Nghiên cứu biến động thành phần loài và sản lượng cá vùng hạ lưu sông Hậu. Tạp chí Khoa học Trường Đại học Cần Thơ. 55(4B), 140-147.

Trương Quốc Phú. (2006). Giáo trình Quản lý chất lượng nước. Trường Đại học Cần Thơ.

Trương Thủ Khoa \& Trần Thị Thu Hương. (1993). Định loại các loài cá nước ngọt vùng Đồng bằng sông Cửu Long. Khoa Thủy sản, Trường Đại học Cần Thơ.

Udupe, K. S. (1986). Statistical method of estimating the size at first maturity in fishes. Fishbyte, The WorldFish Center, 4(2), 8-10.

Vesey, G. \& Langford, T. E. (1985). The biology of the black goby, Gobius niger L. In an English southcoast bay. Journal of Fish Biology, 27, 417-429.

Wright, P. J. \& Trippel, E. A. (2009). Fisheryinduced demographic changes in the timing of spawning: consequences for reproductive success. Fish and Fisheries, 10(3), 283-304. 